\title{
Acil servisten istenen radyolojik görüntüleme incelemelerinin etkinliğinin değerlendirilmesi
}

\section{Evaluation of the effectiveness of radiological imaging examinations ordered from the emergency department}

\author{
Ebru ARSLAN ${ }^{1}$ (D) İrfan AYDIN ${ }^{2 @(D)}$ Uğur LÖK ${ }^{2}$ (D) Umut GÜLAÇTI ${ }^{2}$, Kasım TURGUT ${ }^{2}$ \\ (D) Erdal YAVUZ ${ }^{2}$, Cihad SÖNMEZ ${ }^{2}$ \\ ${ }^{1}$ Adıyaman Eğitim ve Araştırma Hastanesi, 02100, Adıyaman-Türkiye \\ ${ }^{2}$ Adıyaman Üniversitesi, Tıp Fakültesi, Acil Tıp Anabilim Dalı, 02040, Adıyaman-Türkiye
}

Atıf gösterme/Cite this article as: Arslan E, Aydın İ, Lök U, Gülaçtı U, Turgut K, Yavuz E, Sönmez C. Acil servisten istenen radyolojik görüntüleme incelemelerinin etkinliğinin değerlendirilmesi. ADYÜ Sağllk Bilimleri Derg. 2021;7(2):136-145. doi:10.30569.adiyamansaglik.874510

\section{Öz}

Amaç: Acil servisten istenen radyolojik görüntüleme incelemelerinin etkinliği ve görüntülemelerdeki patolojilerin değerlendirilmesi amaçlanmıştır.

Gereç ve Yöntem: 01 Temmuz 2019 ile 01 Ağustos 2019 tarihleri arasında hastanemiz Acil Servisi'ne başvuran ve tanısal amaçlı bilgisayarlı tomografi (BT) ve manyetik rezonans görüntüleme (MRG) istenen hastaların sonuçları retrospektif olarak değerlendirildi.

Bulgular: Çalışmaya toplam 2321 BT ve difüzyon MRG görüntülemesi alınmış olup bunların 2012'si BT, 309'u difüzyon MRG görüntüleme idi.

BT istemlerinin \%23,9'unda, MRG'lerin \%19,1'inde patoloji izlendi.

En s1k BT tipi kranial BT idi $(n=1294,064,3)$. En s1k patoloji abdominopelvik BT'de $(n=262, \% 54,9)$, en az patoloji omurga BT 'de $(n=11, \% 2,3)$ izlendi.

BT istemlerinde, 0-10 yaş grubunda patoloji izlenme sıklığı diğer yaş gruplarından daha düşüktü $(p<0,001)$.

BT veya MRG'de patoloji izlenen hastaların yaş ortalaması patoloji izlenmeyenlerden daha yüksekti (sirasiyla $p<0,001, p=0,039$ )

Sonuç: Acil serviste, hekimlerin ileri görüntüleme tetkiki isterken uluslararası kabul görmüş kılavuzlardan yararlanmasını öneriyoruz.

Anahtar Kelimeler: Acil servis; Bilgisayarlı Tomografi; Manyetik Rezonans Görüntüleme.

\begin{abstract}
Aim: It was aimed to evaluate pathological findings in imaging and the effectiveness of radiological imaging examinations ordered from the emergency department.

Materials and Methods: The results of the patients who applied to the Emergency Service of our hospital between 01, July 2019 and 01, August 2019 and who requested diagnostic computerized tomography $(\mathrm{CT})$ or diffusion magnetic resonance (MRG) were evaluated retrospectively.

Results: A total of 2321 radiological images were included in the study, and of these radiological images, 2012 was CT, and 309 was diffusion MRI. Pathology was observed in $23.9 \%$ of CT imaging and $19.1 \%$ of MRI. The most common type of CT was cranial CT $(n=1294,64.3 \%)$. The most frequent pathologies presence is observed in abdominopelvic CT $(n=262$, $54.9 \%$ ), while the least presence of pathology is observed in spine CT $(n=11,2.3 \%)$. The mean age of patients with pathology in CT or MRI imaging was significantly higher than patients without pathology ( $p<0.001, p=0.039$, respectively).

Conclusion: We recommend that physicians take advantage of the guidelines when ordering advanced imaging in Emergency Department.

Keywords: Emergency department; Computed Tomography; Magnetic Resonance Imaging.
\end{abstract}

Yazışma Adresi/Address for Correspondence: İrfan AYDIN, Adıyaman Eğitim ve Araştırma Hastanesi, 02100, AdıyamanTürkiye, E-mail: irfanaydinyyu@ yahoo.com.tr

Geliş Tarihi/Received:19.02.2021 Kabul Tarihi/Accepted:10.06.2021 Yayım Tarihi/Published online:30.08.2021 


\section{Giriş}

Acil sağlık hizmetleri, sigorta durumu veya sosyoekonomik durumu ne olursa olsun tüm topluma hizmet sunmaktadir. Acil servise herhangi bir şikayetle gelen her hasta, uygun bir şekilde sorgulanmalı ve acil bir durum

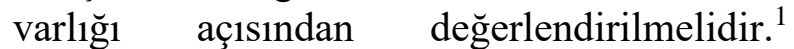
Hastaların acil servis personelinden hizlı bir şekilde hizmet alma ve doğru tanı koymaları konusunda beklentileri vardır. Doktorlardan, acil müdahale gerektirmeyen hastaları doğru bir şekilde filtrelemeleri beklenmektedir. ${ }^{1,2}$

Diğer taraftan acil servisleri etkileyen en kritik konulardan biri yoğunluk sorunudur. $\mathrm{Bu}$ yoğunluk, acil servis sunumunu etkileyen çok yönlü bir konudur. ${ }^{1}$ Bu zorlu ortam, birçok belirsizlikle birlikte, acil doktorlarının klinik tanılardaki hataları en aza indirmek için ileri teknolojiye daha fazla ve klinik becerilerine daha az güvenmelerine yol açmıştır. ${ }^{3}$

Teşhis koymada görüntülemenin öneminin artmas1, bilgisayarlı tomografi (BT) ve manyetik rezonans görüntüleme (MRG) gibi görüntüleme yöntemlerine kolay ulaşabilme imkanıyla birlikte acil servislerde BT başta olmak üzere üst düzey görüntüleme yöntemlerinin kullanımını da arttırmıştır. Bunun sonucunda hastalar ve sağlik personeli radyasyona daha fazla ve yüksek seviyelerde maruz kalma riski ile karşı karşıya kalmıştır. Uygun endikasyon konulmadan yapılan tetkik istemleri, hastaların acil serviste kalış süresini arttırarak acil servis yoğunluğuna yol açmakta ve sağlık harcamalarının artmasına neden olmaktadır. ${ }^{4,5}$

Acil serviste görüntüleme yöntemlerinin aşırı ve gereksiz kullanımı, başka bir merkeze sevk edilen hastalarda (özellikle travma nedenli) tekrarlayan taramalar ve acil servise başvuran hastada uygunsuz ve defansif görüntüleme şeklinde iki ana grupta incelenebilir. Her iki grupta da bu duruma neden olan hasta ilişkili faktörler, hekim ilişkili faktörler ve çevresel-sistemsel faktörler bulunmaktadır. ${ }^{5}$ Aşırı istenen radyolojik tetkikler ve acil servis yoğunluğu arasında çift yönlü ilișki mevcuttur. Son zamanlarda artan malpraktis endişesi de aşırı görüntülemeye neden olan faktörlerin başında gelmektedir., ${ }^{5,6}$
Acil servislerde verimli, güvenli ve etkili bir görüntüleme hizmeti sunmada üç temel faktör göz önüne çıkmaktadır; farkındalık, uygunluk ve denetim. Radyasyonun zararlı etkileri konusunda hem sağlık çalışanları hem de hastalar bilinçlendirilmeli, görüntüleme isterken k1lavuzlara ve uygunluk kriterlerine uyulmalı, rutin klinik denetimlerle kontrolü sağlanmalıdır. Aşırı görüntülemeye neden olan faktörler irdelenerek gerekli düzenlemeler sağlanabilir. Bu sayede hastalar ve sağlık çalışanları radyasyonun zararlı etkilerinden korunabilir, acil servis yoğunluğu bir ölçüde azaltılabilir ve sağlı harcamaları azaltılabilir. $^{4}$

Çalışmamızda, son 1 ay içerisinde çeşitli sebeplerle Adıyaman Eğitim ve Araştırma Hastanesi acil servisine başvurmuş ve BT veya difüzyon MRG istenen hastalar değerlendirilmiştir. Çalışmamızdaki amaç; acil serviste istenen BT ve diffüzyon MRG görüntülemelerinin demografik analizi ile görüntülemelerde patolojinin var olup olmadiğ 1 ve varsa saptanan patolojilerin incelenmesi amaçlanmıştır. Ayrıca bu istemlerin maliyetleri değerlendirilmiştir.

\section{Gereç ve Yöntem}

$\mathrm{Bu}$ çalışma, retrospektif kesitsel bir çalışma olup Adıyaman Üniversitesi Tıp Fakültesi Acil Tıp Anabilim Dalı'nda yapıldı. Çalışma için Adıyaman Üniversitesi Tıp Fakültesi Girişimsel Olmayan Klinik Araştırmalar Etik Kurulu tarafindan $16 / 12 / 2019$ tarih ve 2465 say1l kararı ile etik kurul onayı alındı ve Helsinki İlkeler Deklarasyonuna uyularak gerçekleştirildi.

$\mathrm{Bu}$ çalışmaya 01 Temmuz 2019 ile 01 Ağustos 2019 tarihleri arasında Adiyaman Eğitim ve Araştırma Hastanesi Acil Tıp Servisi'ne başvuran ve tanısal amaçlı BT veya difüzyon $\mathrm{MRG}$ tetkiki istenmiş tüm yaş grubundaki hastalar dahil edildi. BT veya difüzyon MRG istemi olup radyolojik görüntülemesi olmayan, BT veya difüzyon MRG'si olan ancak radyoloji kliniği tarafından raporlanmamış ve görüntüleme verileri eksik olan hastalar çalışma dışında birakıld1.

Hastaların dosyalarından ve hastane bilgi sistemi üzerinden yaş ve cinsiyet bilgileri, BT 
istenen hastalarda tetkik istem nedeni (travmatik, non-travmatik- etiyolojisi belli olmayan vb.), istenen BT tipi (kranial, abdominopelvik, toraks, omurga, ekstremite, tüm vücut, maksillofasial, toraks-anjiyo, orbita, abdomen-anjiyo, boyun, paranazal sinüs, temporal, beyin anjiyo, ekstremite anjiyo), BT veya difüzyon MRG tetkiklerini isteyen hekimin branşı, BT ve difüzyon MRG raporlarının sonuçları, patoloji izlenen hastalarda patolojinin izlendiği vücut bölgesi, izlenen patolojinin ne olduğu, kontrol difüzyon MRG varlığı ve kontrol difüzyon MRG'de patoloji olup olmadığ 1 araştırıldı. Çalışmamızda acil serviste istenen tek MRG tipi difüzyon MRG olduğu için sadece difüzyon MRG sonuçları analiz edilmiştir.

Tetkik sonuçlarında patoloji varlığına göre tetkikler, patoloji olanlar $(+)$ ve patoloji olmayanlar (-) şeklinde ayrıldı. Çalışmanın birincil sonuç ölçütü istenen BT ve diffüzyon MRG görüntülemelerindeki patoloji saptanma oranı idi. Çalışmanın ikincil sonuç ölçütü istenen BT ve diffüzyon MRG görüntülemelerinin demografik analizi ve hastaların verilerinin karşılaştırılması idi.

Analizlerde BT ve difüzyon MRG istenen hastalar; sosyodemografik verileri, görüntüleme sonuçlarında patoloji varlığı ve tetkiki isteyen hekim açısından karşılaştırıldı. Hasta yaşları dekadlara göre ayrılarak tekrar kaydedildi. BT istenen hastalar, kendi grupları içerisinde BT tipleri ve yaş gruplarına göre incelendi. Patoloji izlenen ve izlenmeyen hastalar, her iki grup içerisinde ayrı ayrı tekrar analiz edildi.

\section{İstatiksel analiz}

İstatistiksel analizler SPSS versiyon 20.0 $\left(\mathrm{IBM}^{\circledR}\right.$, Chicago, ABD) ile yapılmıştır. Değişkenlerin normal dağılımına uygunluğu, görsel (histogram ve olasılık grafikleri) ve analitik yöntemler (Shapiro-Wilk testi) kullanılarak incelenmiştir. Tanımlayıcı istatistikler; normal dağılan sayısal verilerde ortalama ve standart sapma, normal dağılmayanlarda ortanca ve alt-üst değer şeklinde, nominal verilerde sayı ve yüzde şeklinde ifade edildi. Normal dağılan değişkenler, iki grup arasında "bağımsız gruplarda t testi" ile; normal dağılmayan değişkenler, iki grup arasında "Mann Whitney U testi" ile analiz edildi. Nominal veriler, iki grup arasında "Ki-kare testi" ve "Fisher exact test" kullanılarak değerlendirilmiştir. Korelasyon analizlerinde "Pearson ve Spearman korelasyon analizleri" tercih edildi. Çalışmadaki istatistiksel analizlerde, $\mathrm{p}$ değeri 0.05 'in altındaki karşılaştırmalar istatistiksel olarak anlamlı kabul edildi.

\section{Bulgular}

Çalışmaya dahil edilen toplam 2321 BT ve MR görüntülemesi yapılmış olan hastaların yaş ortalaması $41,3 \pm 26,6$ y1l $(0-100 \quad$ y1l aralığında) idi. Hastaların \%51,2'si (n=1188) erkek idi. Görüntüleme tetkikleri; hastaların $\% 53,3$ 'ünde $(\mathrm{n}=1237)$ pratisyen hekim, $\% 46,7$ 'sinde $\quad(n=1084)$ acil tıp uzmanı tarafından istenmişti. Hastaların \%76,7'sinde $(n=1781)$ istenen görüntüleme tetkiklerinde patoloji izlenmezken, \%23,3'ünde $(\mathrm{n}=540)$ patoloji izlenmişti.

Çalışmaya dahil edilen toplam $2321 \mathrm{BT}$ ve MR görüntülemesinin \%86,7'sine ( $\mathrm{n}=2012)$ BT, \%13,3 'üne difüzyon MRG $(n=309)$ istenmiş olup BT ve difüzyon MRG istenen hastaların yaş gruplarına göre dağılımı Şekil 1'de gösterilmiştir.

BT istenen hastaların \%41,9'unda $(\mathrm{n}=843)$ travmatik, \%55,9'unda $(\mathrm{n}=1125)$ nontravmatik, \%2,2'sinde $(\mathrm{n}=44)$ ise etiyolojisi bilinmeyen nedenlerle BT istenmişti. Travmatik nedenler çoğunlukla düşme $(\mathrm{n}=705, \% 83,7)$ non-travmatik nedenler ise çoğunlukla nörolojik semptomlar $(\mathrm{n}=604$, $\% 53,6$ ) idi. (Tablo 1) Hastalardan istenen en s1k BT türü $(\mathrm{n}=1294, \% 64,3)$ kranial BT olup diğer BT istemleri sirasıyla abdominopelvik $(\mathrm{n}=502, \% 25,0)$, toraks $(\mathrm{n}=253, \% 12,6)$, omurga $(\mathrm{n}=125, \% 6,2)$ ve ekstremite $(\mathrm{n}=100$, \%5) BT idi.

BT istenen hastaların \%76, '1'inde ( $\mathrm{n}=1531)$ patoloji izlenmezken, MRG istenen hastaların $\% 80,9$ 'unda $(\mathrm{n}=250)$ patoloji izlenmedi. BT ve MRG arasında patoloji varlığı açısından anlamlı farkl1l1k izlenmedi $(p=0,062)$. 


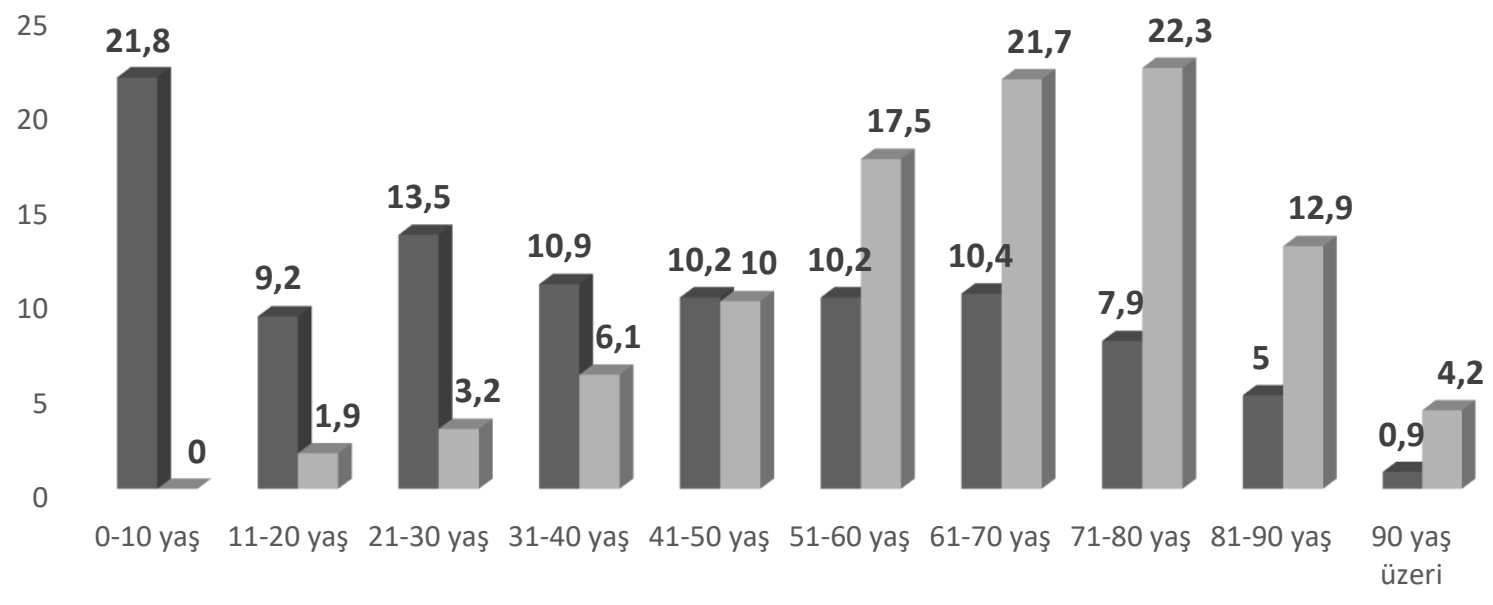

$\square \mathrm{BT} \square \mathrm{MRG}$

Şekil 1. BT ve difüzyon MRG istenen hastaların yaş gruplarına (yıl) göre dağılımı.

Tablo 1. BT çekilen 2012 hastanın BT istem nedenleri.

\begin{tabular}{ll}
\hline BT istem nedeni & $\mathrm{n}(\%)$ \\
\hline Travmatik & $843(41,9)$ \\
Düşme & $705(83,7)$ \\
Trafik kazası & $79(9,4)$ \\
Darp & $44(5,2)$ \\
Diğer* & $14(1,7)$ \\
\hline Non-travmatik & $1125(55,9)$ \\
Nörolojik & $604(53,6)$ \\
Gastrointestinal & $363(32,2)$ \\
Pulmoner & $150(13,3)$ \\
Ürolojik & $35(3,1)$ \\
Diğer** & $28(2,4)$ \\
\hline Etiyolojisi bilinmeyen & $44(2,2)$ \\
\hline * Keskin cisimle yaralanma, göze yabancı cisim batmasl, intihar, iş \\
kazası \\
**Arteryal oklüzyon/ diseksiyon, kardiyak, akut ağr
\end{tabular}

En s1k abdominopelvik BT istenenlerde \%54,5 $(\mathrm{n}=262)$ ve toraks BT istenenlerde \%20,4 (n=98) patoloji izlenmişti. En sik izlenen patolojiler bölgelere göre değerlendirildiğinde abdominopelvik patolojilerden gastrointestinal sistem $(n=94$, \%35,9) hastalıklar1; toraks patolojilerinden plevralefüzyon $(\mathrm{n}=39, \% 39,8)$ ve infiltrasyon $(\mathrm{n}=38, \quad \% 38,8)$; Kranial patolojilerden intrakranial kanama $(\mathrm{n}=17, \% 21,2)$ ve akut iskemi $\quad(\mathrm{n}=17, \% 18,8) ; \quad$ Maksillofasial patolojilerden; inflamatuvar değişiklikler $(\mathrm{n}=23, \% 59)$, nazal kırık $(\mathrm{n}=7, \% 17,8)$; ekstremite patolojilerinden alt ekstremite kırığı $(\mathrm{n}=11, \% 47,9)$; omurga patolojilerinden ise lomber kırık $(\mathrm{n}=8, \% 72,7)$ izlenmişti. BT sonuçlarında izlenen patolojilerin anatomik bölgelere göre dağılımı tablo 2 de gösterilmiştir.
Difüzyon MRG'de patoloji izlenen 59 hastanın \%76,3'ünde $(\mathrm{n}=45)$ akut iskemi, $\% 13,6$ 'sinda $(\mathrm{n}=8)$ kronik iskemi, \%6,8'inde $(n=4)$ şüpheli infarkt alanı, \%3,4'ünde $(n=2)$ kitle izlendi. Alt1 hastaya $(\% 1,9)$ kontrol difüzyon MRG çekildi, sadece bir hastanın $(\% 16,7)$ kontrol difüzyon MRG'sinde patoloji izlendi.

Difüzyon MRG istenen hastaların yaş ortalamas1, BT istenen hastalardan daha büyüktü $(p<0,001)$. BT istenen hastaların $\% 21,7$ 'si $(\mathrm{n}=436)$ 0-10 yaş arasındayken, bu yaş grubunda kimseden MRG istenmemişti. BT istenen hastalarda erkek cinsiyet sıklığı, MRG istenen hastalardan anlaml derecede daha yüksekti $(p=0,021)$. BT istenen hastaların \%54,7'si $(\mathrm{n}=1101)$ pratisyen hekim, $\% 45,3$ 'ü (n=911) acil tıp uzmanı tarafından planlanmıştı. Difüzyon MRG istemi hastaların $\% 44$ 'ünde $\quad(n=136)$ pratisyen hekim tarafindan, \%56'sında ( $\mathrm{n}=173)$ acil tıp uzmanı tarafından planlanmıştı. BT daha çok pratisyen hekimler tarafından istenirken, difüzyon MRG daha çok acil tıp uzmanı tarafından istenmişti $(p=0,018)$. BT veya difüzyon MRG istenen hastaların karşılaştırılması Tablo 3'de gösterilmiştir.

BT istenen hastalarda patoloji izlenenlerin yaş ortalamasının, patoloji izlenmeyenlerden anlamlı derecede daha yüksek olduğu görüldü $(p<0,001)$. Özellikle birinci dekadda çekilen BT'lerde patolojik olma oranı anlamlı derecede düşük bulundu $(p<0,001)$. BT istenen hastalarda, patoloji varlığına göre cinsiyetler 
Arslan E, Aydın İ, Lök U, Gülaçtı U, Turgut K, Yavuz E, Sönmez C. ADYÜ Sağllk Bilimleri Derg. 2021;7(2):136-145.

arasında anlamlı bir farklılık görülmedi $(p=0,122)$. Acil tıp uzmanlarının istediği BT tetkiklerindeki patoloji sıklığı, pratisyen hekimlerinkinden anlamlı derecede daha yüksek bulundu ( $p<0,001$, Tablo 4$)$.

Difüzyon MRG istenen hastalarda, patoloji izlenenlerin yaş ortalamasının patoloji izlenmeyenlerden anlaml derecede daha yüksek olduğu görüldü $(p=0,039)$. Yaş gruplarında, patoloji izlenme oranları açısından anlamlı farklılık olmadığı görüldü. Patoloji varlığı, cinsiyetler arasında farklılık göstermiyordu $(p=0,060)$. Tetkiki isteyen hekimin branşına göre karşılaştırıldığında Acil tıp uzmanlarının istediği difüzyon MRG'lerin sonuçlarında izlenen pozitiflik oranı pratisyen hekimlerinkinden anlamlı derecede daha yüksekti $(p=0,020$, Tablo5).

Tablo 2. BT sonuçlarında izlenen patolojilerin anatomik bölgelere göre dağılımı.

\begin{tabular}{|c|c|c|}
\hline Bölge & Patoloji $(n=481)$ & n (\%) \\
\hline \multirow[t]{8}{*}{ Abdominopelvik } & & $262(54,5)$ \\
\hline & Gastrointestinal & $94(35,9)$ \\
\hline & Ürogenital & $77(29,4)$ \\
\hline & Jinekolojik & $62(23,7)$ \\
\hline & Hepatobiliyer & $51(19,5)$ \\
\hline & Onkolojik & $3(1,1)$ \\
\hline & Solid organ yaralanması & $2(1)$ \\
\hline & Diğer* & $3(1,1)$ \\
\hline \multirow[t]{11}{*}{ Toraks } & & $98(20,4)$ \\
\hline & Plevralefüzyon & $39(39,8)$ \\
\hline & İnfiltrasyon & $38(38,8)$ \\
\hline & Metastaz & $10(10,2)$ \\
\hline & Perikardiyalefüzyon & $9(9,1)$ \\
\hline & Kot fraktürü & $9(9,1)$ \\
\hline & Pnömotoraks & $7(7,1)$ \\
\hline & Kontüzyon & $6(6,1)$ \\
\hline & Pulmoneremboli & $4(4,1)$ \\
\hline & Hemotoraks & $3(3,1)$ \\
\hline & Diğer** & $7(7,1)$ \\
\hline \multirow[t]{10}{*}{ Kranial } & & $80(16,6)$ \\
\hline & Kanama & $17(21,2)$ \\
\hline & Akut iskemi & $15(18,8)$ \\
\hline & Kitle & $14(17,5)$ \\
\hline & Subduralefüzyon & $11(13,7)$ \\
\hline & Kist & $8(10)$ \\
\hline & Fraktür & $8(10)$ \\
\hline & Hidrosefali & $4(5)$ \\
\hline & Parankimalkontüzyon & $3(3,8)$ \\
\hline & Diğer*** & $7(8,8)$ \\
\hline \multirow[t]{9}{*}{ Maksillofasial } & & $39(8,1)$ \\
\hline & İnflamatuar değişiklikler & $23(59)$ \\
\hline & Nazal kırık & $7(17,8)$ \\
\hline & Kitle/kist & $5(12,9)$ \\
\hline & Orbital kırık & $1(2,6)$ \\
\hline & Zigomatik kırık & $1(2,6)$ \\
\hline & Maksiller kırık & $1(2,6)$ \\
\hline & Etmoid kırık & $1(2,6)$ \\
\hline & Temporomandibular kırık & $1(2,6)$ \\
\hline \multirow[t]{5}{*}{ Ekstremite } & & $23(4,8)$ \\
\hline & Alt ekstremite kırığg & $11(47,9)$ \\
\hline & Üst ekstremite kırığ1 & $7(30,4)$ \\
\hline & Alt ekstremiteoklüzyonu & $1(4,3)$ \\
\hline & Pelvis kırı̆̆1 & $1(4,3)$ \\
\hline \multirow[t]{4}{*}{ Omurga } & & $11(2,3)$ \\
\hline & Lomber kırık & $8(72,7)$ \\
\hline & Torakal kırık & $4(36,4)$ \\
\hline & Servikal kırık & $1(9,1)$ \\
\hline
\end{tabular}


Tablo 3. BT veya difüzyon MRG istenen hastaların karşılaştırılması.

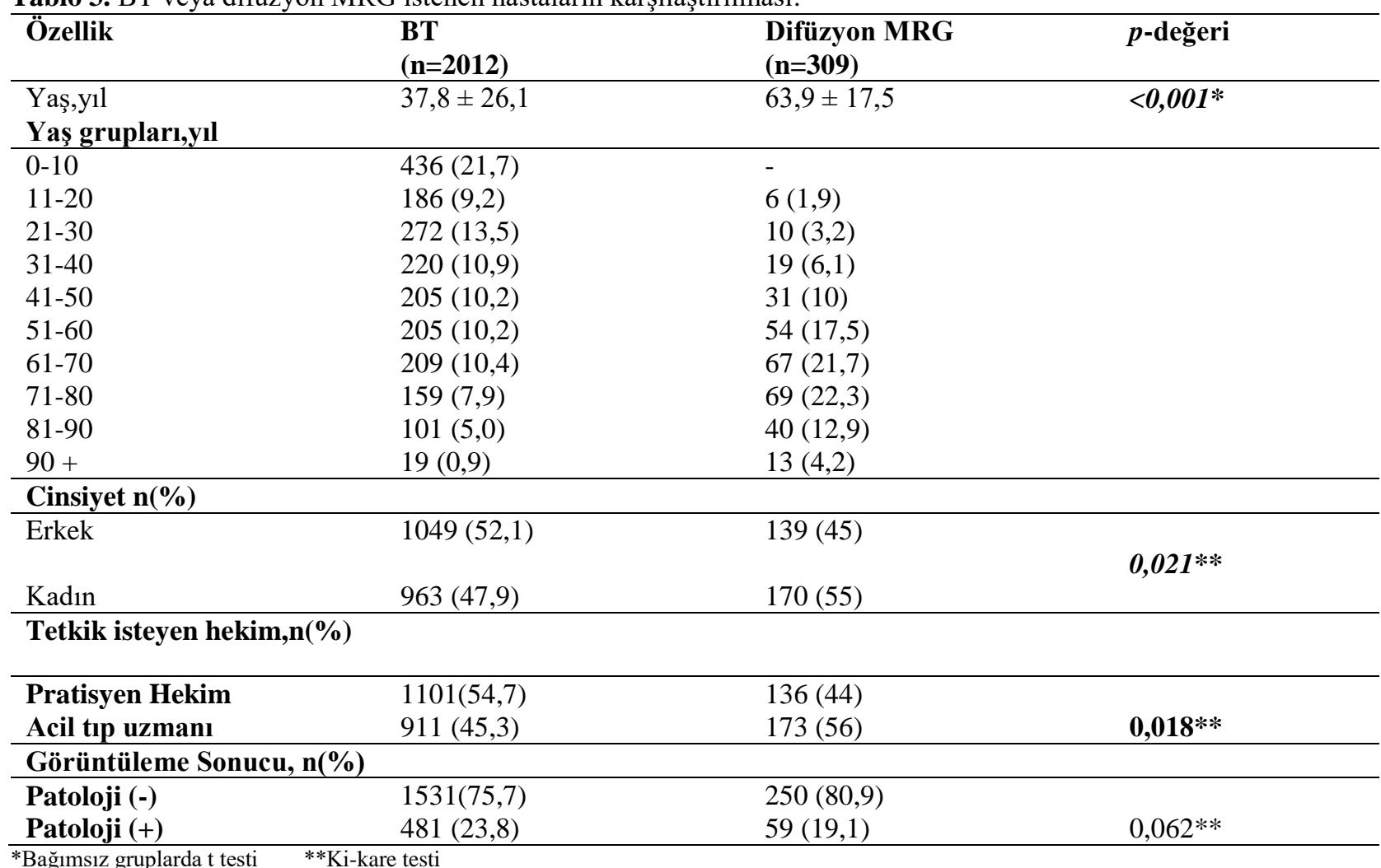

Tablo 4. BT 'de patoloji varlığı ile sosyo-demografik ve klinik özelliklerin ilişkisi.

\begin{tabular}{|c|c|c|c|}
\hline Özellik & $\begin{array}{l}\text { Patoloji (-) } \\
(\mathrm{n}=1531)\end{array}$ & $\begin{array}{l}\text { Patolojii }(+) \\
(n=481)\end{array}$ & $p$-değeri \\
\hline $\begin{array}{l}\text { Yaş, y1l } \\
\text { Ortalama } \pm \text { SS }\end{array}$ & $35,1 \pm 26,2$ & $46,6 \pm 23,8$ & $<0,001 *$ \\
\hline \multicolumn{4}{|c|}{ Yaşgrupları,yıl n(\%) } \\
\hline 0-10 & $410(26,8)$ & $26(5,4)$ & $<0,001 * *$ \\
\hline 11-20 & $135(8,8)$ & $49(10,2)$ & $0,363 * *$ \\
\hline 21-30 & $198(12,9)$ & $76(15,8)$ & $0,110 * *$ \\
\hline $31-40$ & $157(10,3)$ & $63(13,1)$ & $0,081 * *$ \\
\hline 41-50 & $149(9,7)$ & $55(11,4)$ & $0,281 * *$ \\
\hline 51-60 & $152(9,9)$ & $54(11,2)$ & $0,413 * *$ \\
\hline 61-70 & $143(9,3)$ & $65(3,2)$ & $0,009 * *$ \\
\hline 71-80 & $114(7,4)$ & $45(9,4)$ & $0,176^{* *}$ \\
\hline $81-90$ & $65(4,2)$ & $38(7,9)$ & $0,002 * *$ \\
\hline 90+ & $8(0,5)$ & $10(2,1)$ & $0,004 * * *$ \\
\hline Cinsiyet, n(\%) & & & $0,122 * *$ \\
\hline Erkek & $813(53,1)$ & $236(49,1)$ & \\
\hline Kadın & $718(46,9)$ & $245(50,9)$ & \\
\hline \multicolumn{4}{|c|}{$\begin{array}{l}\text { Tetkik isteyen } \\
\text { hekim branşı, } n(\%)\end{array}$} \\
\hline Pratisyen Hekim & $880(57,5)$ & $221(45,9)$ & $<0,001 * *$ \\
\hline Acil Tıp -Uzmanı & $651(42,5)$ & $260(54,1)$ & \\
\hline
\end{tabular}
SS: Standard sapma, *Bağımsız gruplarda t testi, $\quad$ **Ki-kare testi, $\quad$ ***FisherExact test

Hastanemizdeki difüzyon MRG ve BT maliyetlerine göre istenen tetkiklerin maliyeti hesapland1. Buna göre toplam difüzyon MRG maliyeti 40170,00 TL, toplam BT maliyeti 396642,00 TL olarak hesaplandı. Patoloji saptanmasına göre görüntülemeler dikkate alındığında; patoloji izlenmeyen difüzyon MRG maliyeti 32500,00 TL, patoloji izlenmeyen BT maliyeti 287643,00 TL olarak hesapland1. 
Tablo 5. Difüzyon MRG'dapatoloji varlığı ve sosyo-demografik-klinik özelliklerin ilişkisi.

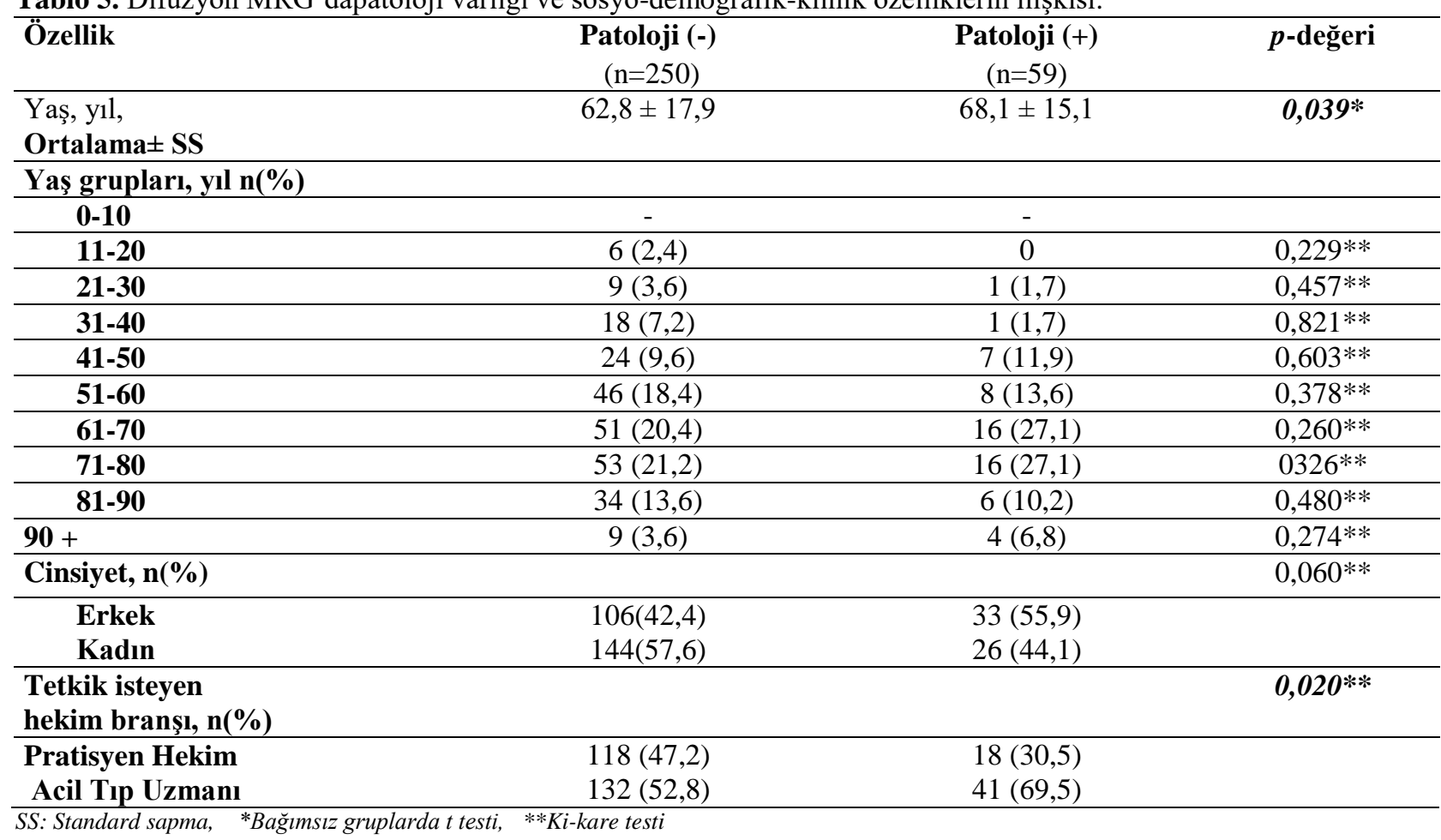

\section{Tartışma}

Acil servislerde görüntüleme yöntemlerinin kullanımındaki artış, uluslararası anlamda dikkat çekmeye başlamıştır. $\mathrm{Bu}$ artışı inceleyen çalışmaların bir kısmında, özellikle BT kullanımındaki artışa rağmen elde edilen kar/zarar oranında belirgin artış olmadığı ifade edilmiştir. ${ }^{7,8}$ Bununla birlikte acil servislere başvuru oranının yaklaşık 15 yıl içerisinde iki katına çıktığı yönünde veriler bulunmaktadır. Başvuru sayısındaki artış ise, tetkik istemleri üzerinde lineer bir artışla sonuçlanmaktadır. ${ }^{9}$

Çalışmamızda, BT istemlerinin \%20'sinin 0-10 yaş arasındakiler için istenmesinde bazı nedenler etkili olmuş olabilir. Özellikle yenidoğan ve infantlarda nörolojik muayenenin zor olması, mevcut bulguların her zaman spesifik olmaması, ebeveynlerin kaygısı, ayırıcı tanıların daha kesin şekilde dışlanmak istenmesi ve malpraktis korkusu gibi nedenler bu yaş grubunda istem sıklığını arttırabilmektedir. ${ }^{10}$ Malpraktis davalarının yüksek meblağlı olması malpraktis kaygısını arttırdığı düşünülebilir.

Çocuklarda BT istem nedenlerinin başında minör kafa travmaları yer almaktadır. Ancak minör kafa travmalarının yaklaşık \%5'inde intrakranial bir patoloji izlenmektedir. ${ }^{11}$
Pediyatrik travma hastalarında Glasgow koma skorunun 13'ün altında olması, fokal nörolojik defisit ve bilinç değişikliği durumunda BT çekilmesi önerilmektedir; ancak daha hafif vakalar için bir uzlaşı sağlanamamıştır. ${ }^{12}$

İstenen ileri görüntüleme kullanımının oranı, etkinliği ve sonuçları önemli bir araştırma konusudur. Avrupa Birliği (AB) Sağlık İstatistikleri raporuna göre Türkiye; 2011-2014 y1llar1 arasinda MRG taramalarında birinci, BT taramalarında ise 8 . sırada yer aldı. BT kullanımında AB ortalamasındaki artış \%49 olurken, Türkiye'de artış \%60 oldu. MRG kullanımında AB ortalamasında artış \%38 olurken, Türkiye'de $\% 134$ artıș oldu. ${ }^{13}$

Acil servislerde ise, Oğuz ve ark'ının çalışmasında 1998 yılında acil servise başvuran hasta sayısı 2000 yılında \%3,6 artış gösterirken, BT istem sıklı̆̆ında \%69 artış izlenmiştir. Çalışmada kranial, maksillofasial ve servikal BT görüntülemelerinde, 2000 yılında normal sonuçlar artış gösterirken, majör bulgularda ve minör bulgularda azalma izlenmiştir ${ }^{14}$. Çalışmamızın primer amacı, acil serviste bir ay içerisinde istenen BT ve diffüzyon MR görüntülemelerinin ne kadarında patoloji izlendiğini göstermekti. Çalışmamızda yıllara göre istenen tekik sayısı 
araştırılmadı. Fakat bulgularımız, acil servislerde istenen tanısal görüntülemelerin çoğunun normal sonuçlandığına işaret etmekteydi.

Y1ldız ve ark'1 tarafindan 2019 yılında Bursa'da yapılan çalışmada, ikinci basamak bir hastanenin acil servisine başvuran ve tanisal olarak BT istenen 1700 hasta incelenmiştir. ${ }^{15}$ Çalışmada travma nedeniyle en sik kranial BT istenmişti. Kranial BT istenen hastaların \%7'sinde, toraks BT istenen hastaların \%10,7'sinde, abdominopelvik BT istenenlerin \%7,9'unda patoloji izlenmişti. Ayrıca çalışmada, çocukluk yaş döneminde travma nedeniyle yapilan kranial görüntülemelerin $\% 98,5$ 'inde patoloji izlenmediği ifade edilmiştir. Tüm nedenler dikkate alındığında abdominopelvik BT'lerin yaklaşık \%65'inde patoloji izlenmişti. Çalışmamızda, benzer şekilde kranial BT en sık istenen BT türüydü. Çalışmamızda izlenen kranial BT ve abdominopelvik BT sonuçlarında patoloji varlığı, bu sonuçlarla benzer düzeydeydi.

Ozturk ve ark'ının 2018 yılındaki çalışmasında, senkopla acil servise başvuran hastalardan MRG veya BT istenenler incelenmiş, hastalardan sadece \%3,8'inde görüntüleme sonucunda anormal patolojiler izlenmiştir. ${ }^{16}$ Çalışmanın sonucunda senkopla acil servise başvuran hastalarda, kranial BT'lerin rutin kullanımında azalma sağlayacak yöntemlerin araştırılması gerektiği bildirilmiştir. Benzer şekilde, Kapoor ve ark'1, senkop şikayetiyle acil servislere başvuran hastaların \%4'ünde BT'nin fayda sağladığını ifade etmiştir. ${ }^{11}$ Goyal ve ark'1 ise, senkopla acil servise başvuran 117 hastanın hiçbirinde kranial BT'de patoloji izlenmediğini ifade etmiştir. ${ }^{17}$ Ancak bu çalışmada travma, nöbet, mental durum değişikliği ve fokal nörolojik defisit varlığı olan hastalar çalışmadan dişlanmıştır.

Swartzberg ve Goldstein, 2018 y1lında 4 aylık bir süre içerisinde yetişkin acil servise başvuran hastalarda BT istemlerini değerlendirmiştir. ${ }^{18}$ Başvuran hastaların \%4,6'sında BT istenen çalışmada, tetkiklerin çoğu travma hastalarından istenmiştir. Kranial BT'lerin çoğunluğu oluşturduğu çalışmada, tüm BT'lerin \%53,8'inde pozitif sonuçlara ulaşılmıştır. Travma hastalarında bu oran $\% 47,1$, non-travma hastalarında ise $\% 61,8$ olarak bildirilmiştir. Bu bulgular ışı ğında acil serviste istenen görüntülemelerin; sadece ülkemizde değil diğer ülkelerde de yapılan çalışmalarda yüksek oranda negatif sonuçlandığ boyutta değil, global anlamda sorun teşkil ettiği söylenebilir.

Acil servislerde kranial BT ve difüzyon MRG tetkikleri s1klıkla birlikte istenmektedir. Hammoud ve ark'ının 2016 yılındaki çalışmasında, acil servise atipik inme semptomlarıyla başvuran BT görüntülemesi negatif 152 hasta MRG görüntüleme ile de değerlendirilmiştir. ${ }^{19}$ Çalışmada hastaların sadece \%11,5'inde MRG görüntüleme ile akut veya subakutinfarkt tespit edilmiştir. Pozitif MRG sonuçlarında; hiperlipidemi, hipertansiyon, diyabet, antikoagülan kullanımı ve inme öyküsünün belirleyici olduğu bildirilmiştir. MRG bulguları pozitif olan olguların yaşlarının, negatif olanlara kıyasla daha fazla olduğu (74,1 yıl \& 57,5 yıl) görülmüştür. Benzer şekilde $\mathrm{MRG}$ görüntülemesi pozitif olan hastaların daha yaşlı olduğu, çalışmamızda da izlenmiştir. Acil servis hekimleri hastaların tanı sürecinde bir taraftan en hızlı ve en doğru tanıyı bulmakla yükümlüyken, diğer taraftan tetkiklerin maliyeti ve tetkik ilişkili zararların oluşturduğu bir üçgen içerisinde sıkışmaktadır. Tetkik maliyetlerinin de düşürülmesi adına, yaşlı ve kardiyovasküler hastalıkları olan hastalarda MRG görüntüleme dikkate alınabilir. Ayrıca çalışmamızda izlenen diğer önemli bir bulgu, acil tıp uzmanlarının istediği BT veya difüzyon MRG tetkiklerinin, pratisyen hekimlerinkinden daha çok pozitif sonuçlanmasıdır. Acil tıp uzmanlarının daha üstün eğitimleri, $\mathrm{MRG}$ görüntüleme için bildirilen kılavuzlara daha fazla uyum içerisinde olmaları ve daha fazla tecrübeye sahip olmaları görüntüleme sonuçlarının daha yüksek oranda pozitif olmasıyla sonuçlanmış olabilir. Bulgularımız ışığında, ileri görüntülemelerin acil tıp uzmanları tarafindan istenmesi yahut radyoloji bölümüyle tetkik istemi konusunda iş birliği yapılması ve radyolojik eğitimlerin 
arttırılması yoluyla sağlık maliyetlerinin azalacağı söylenebilir.

Çalışmamızda difüzyon MRG istenen hastaların sadece 6'sina tekrar MRG istenmişti. $\mathrm{Bu}$ hastaların sadece birinde patoloji izlenmişti. Tekrarlayan MRG istemlerinin çalışmamızda oldukça nadir olduğu görüldü. Literatürde fazladan tekrarlayan çekimlerin; maliyeti, görüntüleme ilişkili zararlara maruziyeti arttırdığı ve acil serviste kalış süresini uzattı̆̆ bildirilmiştir. Tung ve ark'1 2018 yılında yaptıkları derlemede tekrarlayan çekimlerde etkili olan faktörlerin; görüntülerin travma merkezine ulaşmaması, ulaşan görüntülerin yeterli kalitede olmaması, hekimlerin tercihi, tekrarlı çekimlerin spesifik hastalarda rutin bakımın bir parçası olması ve konsültan hekimin isteği şeklinde bildirmiştir. ${ }^{5}$ Ayrıca 65 yaşından büyük hastalar, küçük yaştaki çocuklar, yaralanma skoru yüksek olanlar, yaralanma mekanizması, sağlık güvencesinin olmas1, travma merkezine olan uzaklık ve hastanın hava taşımacılığ 1 ile transferinin görüntüleme istemini arttırabileceği ifade edilmiştir.

BT görüntülemenin fazla istenmesinin önüne geçilmesi için bazı önlemler önerilmiştir. Travma hastalarında merkezi sinir sistemi görüntülemesinde "New Orleans" ve "Canadian CT HeadRule" kritelerinin yüksek sensitiviteye sahip olduğu ifade edilmiştir. Non-travmatik hastalar için de benzer rehberler tanımlanmıştır. ${ }^{20}$ Kanzaria ve ark'ının 2015 yılındaki çalışmasında, 435 acil servis hekimi değerlendirilmiştir. Çalışmada hekimlerin \%85'i çalıştıkları acil serviste çok fazla tanısal test istendiğine inandıklarını belirtmişlerdir. Hekimlerin neredeyse tamamı istedikleri ileri görüntülemelerin bazılarının medikal olarak gereksiz olduğunu ifade etmiştir. Hekimler gereksiz düşündükleri bu fazladan istenen görüntüleme tetkik sayılarının; malpraktis reformu, hastaların eğitilmesi, test isteme konusunda hekimlere geri dönüş sağlanması ve hekimlerin tanısal görüntüleme testleri hakkında eğitilmesi ile azaltılabileceğini belirtmiştir. ${ }^{21}$

Çalışmamızda maliyetler bir ay süre içerisinde patoloji izlenmeyen difüzyon $\mathrm{MRG}$ için 32500,00 TL, patoloji izlenmeyen BT için 287463,00 TL olarak hesaplanmıştır. Acil serviste BT ve difüzyon MRG'nin ylllı maliyeti ise yaklaşık 4 milyon TL'yi bulmaktadır. $\mathrm{Bu}$ nedenle patoloji saptanmayan BT ve difüzyon MRG'lerin önemli bir sağlık maliyetine neden olduğu söylenebilir.

\section{Araştırmanın kısıtlılıkları}

Çalışmamızın bazı kısıtlılıkları vardı. Birincisi, difüzyon MRG ve BT istemleri sadece bir aylık süre içerisindeki başvurular için değerlendirilmiştir. Daha uzun süreli bir değerlendirme daha kapsamlı sonuçlar verebilirdi. İkincisi, bu çalışma, retrospektif olarak yapılan bir çalışma olmasından dolayı hastaların klinik bulguları değerlendirilememiştir. Bunun yerine tetkik istem gerekçesi belirtilmiş ve tetkik sonuçlarında patoloji izlenip izlenmemesi dikkate alınmıştır. Çalışmamızdaki diğer bir kısitlılık da hasta sayısına göre BT ve difüzyon $M R G$ istem sıklığı ve acil servis hasta yoğunluğu değerlendirilememiştir.

Hastaların klinik bulguları ve acil servis hasta yoğunluğu verilerini de kapsayacak olan yeni çalışmalarla; ülkemizde acil servislerde BT ve MRG istem siklıkları, acil servis hekimlerinin BT ve MRG istem nedenleri, malpraktis korkusu ve defansif tıbbın ülkemizdeki boyutu değerlendirilebilir.

\section{Sonuç}

En s1k istenen BT türünün kranial BT olması, ancak en yüksek negatif sonuçların kranial BT'de izlenmesi, özellikle kranial BT istemlerinde dikkatli olunması ve kranial BT istem nedenlerinin iyi analiz edilmesi gerektiğine işaret etmektedir. Ayrıca acil serviste fazla sayıda istenen ve patoloji saptanmayan BT ve difüzyon MRG tetkikleri, sağlık harcamalarında ciddi bir maliyet oluşturmaktadır.

Hekimlerin radyolojik görüntüleme isterken uluslararası kabul görmüş kılavuzlardan yararlanması, tetkik istemlerinin sayısının ve sağlık masraflarının azalmasını sağlayabilir.

\section{Araştırmanın Etik Boyutu}


Çalışma için Adıyaman Üniversitesi Tıp Fakültesi Girişimsel Olmayan Klinik Araştırmalar Etik Kurulu tarafından 16/12/2019 tarih ve 2465 sayılı kararı ile etik kurul onayı alındı ve Helsinki İlkeler Deklarasyonuna uyularak gerçekleştirildi.

\section{Bilgilendirilmiş Onam}

Çalışmamız retrospektif çalışma olduğundan bilgilendirilmiş hasta onamı alınmadi.

\section{Yazar katkıları}

Fikir, tasarım: E.A, İ.A Verilerin toplanması ve işlemesi, analiz ve yorum: U.G, K.T, E.Y Literatür taraması: E.A, C.S Makale yazımı: E.A, İA, U.G Eleştirel inceleme: E.Y, K.T

\section{Çıkar Çatıșması Beyanı}

Yazarların herhangi bir çıkara dayalı ilişkisi yoktur.

\section{Araştırma Desteği}

Çalışmayı maddi olarak destekleyen kişi/kuruluş yoktur.

\section{Hakem Değerlendirmesi}

Diş bağımsız.

\section{Kaynaklar}

1. Rasouli HR, Aliakbar Esfahani A, Abbasi Farajzadeh M. Challenges, consequences, and lessons for way-outs to emergencies at hospitals: a systematic review study. $B M C$ Emerg Med. 2019;19(1):62.

2. Hinson JS, Martinez DA, Cabral S, et al. Triage Performance in Emergency Medicine: A Systematic Review. Ann Emerg Med. 2019;74(1)

3. Larson DB, Johnson LW, Schnell BM, Salisbury SR, Forman HP. National trends in CT use in the emergency department: 1995-2007. Radiology. 2011;258:164-173.

4. Azman RR, Shah MNM, Ng KH. Radiation Safety in Emergency Medicine: Balancing the Benefits and Risks. Korean J Radiol. 2019;20(3):399-404.

5. Tung M, Sharma R, Hinson JS, et al. Factors associated with imaging overuse in the emergency department: A systematic review. Am J Emerg Med. 2018;36(2):301-309.

6. Ferguson B, Geralds J, Petrey J, Huecker M. Malpractice in Emergency Medicine-A Review of Risk and Mitigation Practices for the Emergency Medicine Provider. J Emerg Med. 2018;55(5):659-665.

7. Korley FK, Pham JC, Kirsch TD. Use of advanced radiology during visits to US emergency departments for injury-related conditions, 1998-2007. JAMA. 2010;304(13):1465-1471.

8. Wiener RS, Schwartz LM, Woloshin S. Time trends in pulmonary embolism in the United States: evidence of overdiagnosis. Arch Intern Med. 2011;171(9):831-7.

9. Raja AS, Ip IK, Sodickson AD, et al. Radiology utilization in the emergency department: trends of the past 2 decades. AJR Am J Roentgenol. 2014;203(2):355-360.

10. Quayle KS, Jaffe DM, Kuppermann N et al. Diagnostic testing for acute head injury in children: when are head computed tomography and skull radiographs indicated? Pediatrics. 1997;99(5, article e11).
11. Kapoor WN, Karpf M, Wieand S, Peterson JR, Levey GS. A prospective evaluation and follow-up of patients with syncope. N Engl J Med. 1983;309(4):197-204.

12. Simon B, Letourneau P, Vitorino E, McCall J. Pediatric minor head trauma: indications for computed tomographic scanning revisited. Journal of Trauma. 2001;51(2):231-238.

13. Demir MC, Akkas M. Awareness of Risks Associated with the Use of Plain X-Ray, Computed Tomography, and Magnetic Resonance Imaging Among Emergency Physicians and Comparison with that of Other Physicians: A Survey from Turkey. Med Sci Monit. 2019;25:6587-6597. doi: 10.12659/MSM.918381.

14. Oguz KK, Yousem DM, Deluca T, Herskovits EH, Beauchamp NJ. Effect of emergency department CT on neuroimaging case volume and positive scan rates. Acad Radiol. 2002;9(9):10181024.

15. Yıldız Ö, Eraybar S, Kaya H, Armağan E. Acil serviste yapılan bilgisayarlı tomografi görüntüleme istemleri ne kadar etkin? $J$ Contemp Med. 2019; 9(3): 249-254.

16. Ozturk K, Soylu E, Bilgin C, Hakyemez B, Parlak M. Predictor variables of abnormal imaging findings of syncope in the emergency department. Int J Emerg Med. 2018;11(1):16.

17. Goyal N, Donnino MW, Vachhani R, et al. The utility of head computed tomography in the emergency department evaluation of syncope. Intern Emerg Med. 2006;1(2):148-150.

18. Swartzberg K, Goldstein LN. High positive computed tomography yields in the emergency department might not be a positive finding. S Afr Med J. 2018;108(3):230-234.

19. Hammoud K, Lanfranchi M, Li SX, Mehan WA. What is thediagnosticvalue of head MRI afternegativehead CT in ED patientspresentingwithsymptomsatypical of stroke? Emergency radiology.2016; 23(4), 339-344.

20. Stiell IG, Wells GA, Vandemheen K, et al. The Canadian CT Head Rule for patients with minor head injury. Lancet. 2001;357(9266):1391-1396.

21. Kanzaria HK, Hoffman JR, Probst MA, et al. Emergency physician perceptions of medically unnecessary advanced diagnostic imaging. Acad Emerg Med.2015;22(4):390-398. 